Check for updates

Cite this: RSC Adv., 2017, 7, 26858

Received 10th February 2017

Accepted 8th April 2017

DOI: 10.1039/c7ra01711a

rsc.li/rsc-advances

\section{Multifunctional polyurethane-vitrimers completely based on transcarbamoylation of carbamates: thermally-induced dual-shape memory effect and self-welding $\dagger$}

\author{
Peiyao Yan, (D) Wei Zhao, Xiaowei Fu, Zhimeng Liu, Weibo Kong, Changlin Zhou* \\ and Jingxin Lei ${ }^{*}$
}

Environmental protection and resources exhaustion have become the two major obstacles that the human race faces. Moreover, conventional thermoset polymers, which have been extensively applied in various fields, are difficult to be reprocessed and recycled thereby resulting in a wastage of resources and environmental pollution owing to their chemical crosslinks. Therefore, vitrimers may be a good option to solve this problem. In this study, renewable castor oil was used as the raw material to synthesize multifunctional polyurethane-vitrimers (PUVs), whose intrinsic carbamate bonds undergo transcarbamoylation reactions in the presence of a catalyst. Reprocessing experiments have shown that reprocessed PUVs have nearly the same excellent tensile property compared with the pristine PUVs and have significant potential for future engineering applications. Subsequent studies have indicated that crosslinked networks have properties of thermally-induced dual-shape memory effect (dual-SME) and self-welding due to transesterification reactions of carbamate bonds. As the current methods of dealing with abandoned thermoset polyurethanes have drawbacks, it can be anticipated that our findings will create significant benefits for our life.

\section{Introduction}

Conventional polymer materials can be classified into two major categories based on their thermal behavior: thermoplastics and thermosets. ${ }^{1}$ Thermoplastic polymers can be melted reversibly and solidified due to their linear structure or branches. ${ }^{2,3}$ On contrary, due to the chemically crosslinking structure, thermosets cannot be reshaped, reprocessed or recycled, resulting in a serious environmental pollution and waste of resources due to accumulation of discarded materials. However, they are still irreplaceable due to their superior dimensional stability, chemical resistance and mechanical properties. ${ }^{4,5}$

Thus, the study on reprocessing/recycling of thermosetting materials and preparing environment friendly polymers from renewable resources has gained attention. Leibler et al. have successfully synthesized a reprocessed thermosetting epoxy resin similar to thermoplastic materials, ${ }^{6}$ which has broken the restraint on thoughts that thermosetting resin is difficult to be reprocessed. Further study suggested that this polymer has

State Key Laboratory of Polymer Materials Engineering, Polymer Research Institute of Sichuan University, Chengdu 610065, China.E-mail: chouscu@scu.edu.cn; jxlei@scu. edu.cn

$\dagger$ Electronic supplementary information (ESI) available: Experimental method, characterization and supplementary figures. See DOI: 10.1039/c7ra01711a a silica-like rheological property. ${ }^{7,8}$ Accordingly, he proposed the term "vitrimer" to describe this class of materials, known as "third type of polymer materials". ${ }^{9}$ Similar to traditional thermosetting materials, these materials possess high temperature resistance and solvent resistance due to their chemical crosslinking structure. The difference is that the dynamic chemical bonds are introduced into this material system, and the exchange reaction can be caused by the application of stress under a high temperature or the presence of a catalyst. This results in topological changes, and hence the reprocessing of the thermosetting material can be realized. ${ }^{10-15}$ Beyond that, dynamic chemical bonds endow some other outstanding properties to the materials, including multi-shape memory, self-welding, etc. ${ }^{16-21}$ In particular, the network polymer tends to obtain thermally-induced dual-SME, which contains a recoverable elasticity-based shape deformation through entropy changes and a permanent plasticity-based shape deformation via topological changes. ${ }^{22-26}$

Consequently, a large number of researchers have set their sights on vitrimers to tackle environmental problems. Among which, epoxy vitrimers have received extensive attention and only few reports on other types of vitrimers are available in the literature. Moreover, vitrimers of polyurethane have been reported only in a few studies and have not drawn enough attention for potential applications. W. R. Dichtel et al. ${ }^{27}$ were 
the first ones to apply six-membered cyclic carbonates and polyfunctional amines for the synthesis of cross-linked polyurethanes containing free hydroxyl groups as a new class of vitrimers (PHUs). However, they have considered that classical transcarbamoylation processes are sluggish for carbamates and PUVs could not be achieved unless additional dynamic functional groups were incorporated to this system. Moreover, synthetic process of PHUs is quite tedious and lengthy. In addition, T. Xie et al. ${ }^{23}$ have found a classical thermoset shapememory polyurethane that was readily capable of permanent reshaping (plasticity) through topological network changes induced by transcarbamoylation in presence of a catalyst, which inspired us to prepare PUVs completely based on transcarbamoylation of carbamates.

In the present investigation, we prepared PUVs completely based on transcarbamoylation of carbamates with properties of thermally dual-SME and self-welding via classical polyurethane chemistry: reaction of polyethylene glycol (PEG, $M_{\mathrm{n}}=2000$ ), castor oil (CO) and hexamethylene diisocyanate (HDI), using dibutyltin dilaurate (DBTDL) and ethyl acetate (EA) as catalyst and solvent, respectively. DBTDL is a common and economic catalyst, $\mathrm{CO}$ is bio renewable raw material, ${ }^{\mathbf{2 8 , 2 9}}$ and EA is an industrially and widely utilized solvent or raw material. ${ }^{30,31} \mathrm{We}$ studied the reprocessing properties of PUVs with $1 \mathrm{wt} \%, 2 \mathrm{wt} \%$ and 3 wt $\%$ catalyst (PUV-1, PUV-2 and PUV-3, respectively) under the same process conditions and quantitatively discussed the mechanical properties of pristine PUVs and reprocessed PUVs. We also explored the behavior of thermally-induced dualSME and self-welding. The stress relaxation, thermomechanical properties and ability of elasticity and plasticity shape memory were characterized by dynamic mechanical thermal analyses (DMA). The thermal and mechanical

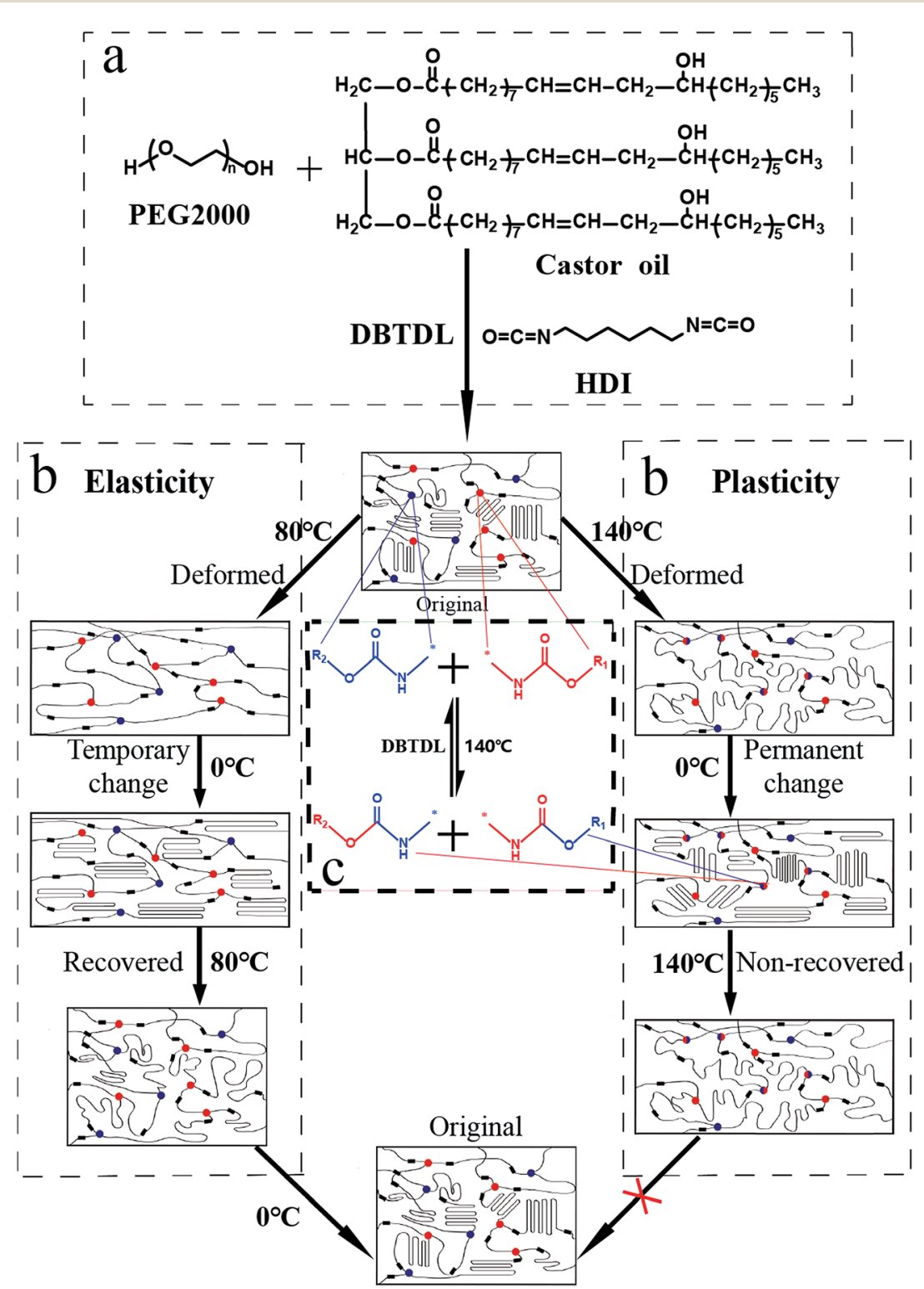

Fig. 1 (a) Chemical structures of raw materials. (b) Illustration of the property of elasticity/plasticity shape memory. (c) Transcarbamoylation reaction of carbamate bonds. 
properties were assessed by thermogravimetric analysis (TGA), differential scanning calorimetry (DSC) and tensile tests. Moreover, some intuitive photographs displaying the reprocessing, shape memory and self-welding of PUVs are presented.

\section{Experimental}

\section{Materials}

Polyethylene glycol (PEG, analytical grade, $M_{\mathrm{n}}=2000$ ), castor oil (CO, analytical grade, hydroxyl number equals $163 \mathrm{mg} \mathrm{KOH} \mathrm{per}$ $\mathrm{g}$ ), catalyst dibutyltin dilaurate (DBTDL) and ethyl acetate (EA, analytical grade) were purchased from Chengdu Kelong Chemical Reagent Co. Ltd., China. PEG and CO were dried under vacuum at $100{ }^{\circ} \mathrm{C}$ for $10 \mathrm{~h}$ before use. Hexamethylene diisocyanate (HDI, 99.6\% pure) was obtained from Aladdin Chemistry Co. Ltd., China. All the materials were used without further purification.

\section{Synthesis of PUVs}

Herein, $10 \mathrm{~g}$ of melted PEG, $3.8 \mathrm{~g}$ of CO and $5 \mathrm{~g}$ of EA were added into a three neck round bottomed flask fitted with an overhead stirrer and a condenser pipe at $60{ }^{\circ} \mathrm{C}$. After mixing for $10 \mathrm{~min}$, a stoichiometric amount of HDI and predetermined amount of DBTDL ( $1 \mathrm{wt} \%, 2 \mathrm{wt} \%$ and $3 \mathrm{wt} \%$ ) were added into the bottle. The reaction mixture was poured into a glass pan after stirring for another 2 min. Finally, PUVs were obtained after thermal curing at $50{ }^{\circ} \mathrm{C}$ for $4 \mathrm{~h}$ in an oven and dried in vacuum at $100{ }^{\circ} \mathrm{C}$ for $6 \mathrm{~h}$.

\section{Reprocessing experiments}

PUVs were reprocessed on a $0.63 \mathrm{M}$ Newton pressure forming machine (China). The small particles of PUVs were placed in a dimension of $8 \mathrm{~cm}$ length $\times 8 \mathrm{~cm}$ width $\times 1 \mathrm{~mm}$ thickness rectangular mold and were treated for $2 \mathrm{~h}$ without vacuum under $10 \mathrm{MPa}$ pressure at $180^{\circ} \mathrm{C}$. Then, the polymers were cold pressed under $10 \mathrm{MPa}$ for $7 \mathrm{~min}$ and the mold was unloaded.

\section{Characterization}

Fourier transform infrared spectroscopy (FTIR). The structures of CO, PEG, pristine PUVs and reprocessed PUVs were measured using Nicolet-560 infrared spectrophotometer (USA). All samples were collected in the wavenumber range of 4000$400 \mathrm{~cm}^{-1}$ by 32 scans with $4 \mathrm{~cm}^{-1}$ resolution. The $\mathrm{KBr}$ pressed disc technique (about $1 \mathrm{mg}$ of sample and $100 \mathrm{mg}$ of $\mathrm{KBr}$ ) was used for sample preparation of PEG and CO. The pristine PUVs and reprocessed PUVs were measured by attenuated total reflectance infrared spectroscopy (ATR-IR).

Dynamic thermal mechanical analyses (DMA). The thermal mechanical properties of PUVs were measured using dynamic
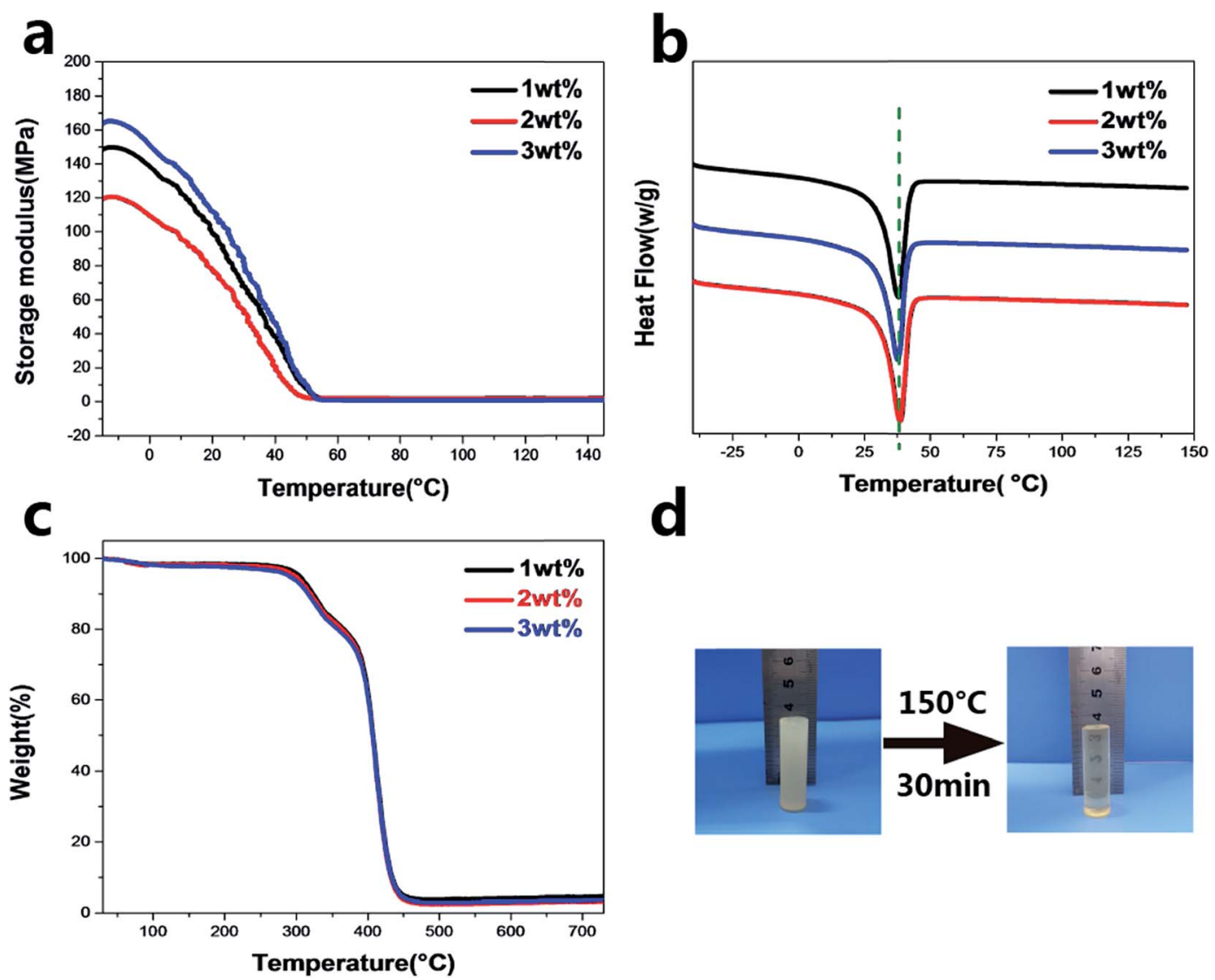

Fig. 2 (a) Storage modulus ( $\left.E^{\prime}\right)$ vs. temperature curves of the PUVs. (b) Differential scanning calorimeter (DSC) curves of the PUVs. (c) Thermogravimetric analysis (TGA) of the PUVs in nitrogen atmosphere. (d) Melting experiment of the crosslinked PUV-3. 
mechanical analyzer (DMA Q800, USA), heated from $-15{ }^{\circ} \mathrm{C}$ to $150{ }^{\circ} \mathrm{C}$ at a rate of $3{ }^{\circ} \mathrm{C} \mathrm{min}{ }^{-1}, 0.2 \%$ strain and a frequency of $1 \mathrm{~Hz}$ in stretch. All samples were cut into rectangular-shape of dimensions $15 \mathrm{~mm}$ length $\times 5 \mathrm{~mm}$ width $\times 1 \mathrm{~mm}$ thickness.

Thermogravimetric analysis (TGA) and differential scanning calorimetry (DSC). The thermal stability of PUVs were examined on a thermal gravimetric analyzer (SDTQ600, USA) under nitrogen from room temperature to $800{ }^{\circ} \mathrm{C}$ at a heating rate of $10{ }^{\circ} \mathrm{C} \mathrm{min}^{-1}$. About $6 \mathrm{mg}$ of specimens were used for each measurement. DSC of PUVs was conducted on differential scanning calorimeter (DSC 8500 PerkinElmer, USA) from -45 to $150{ }^{\circ} \mathrm{C}$, from 150 to $-45^{\circ} \mathrm{C}$, and then from -45 to $150{ }^{\circ} \mathrm{C}$ with heating/cooling rate of $10{ }^{\circ} \mathrm{C} \mathrm{min}{ }^{-1}$ for about $8 \mathrm{mg}$ of samples. The second heating ramps were shown in previously reported literature.

Tensile tests. The mechanical properties of pristine PUVs and reprocessed PUVs were observed on a universal testing machine (INSTRON 4302, 10KN, USA). The crosshead rate was found to be $30 \mathrm{~mm} \mathrm{~min}^{-1}$ at room temperature, and the dogbone type dimensions were prepared according to ISO527-2/5A.

The creep and stress relaxation tests. The creep and recoveries of PUV-3 were measured using dynamic mechanical analyzer (DMA Q800, USA) at $130{ }^{\circ} \mathrm{C}, 140{ }^{\circ} \mathrm{C}$ and $150{ }^{\circ} \mathrm{C}$. The samples were stretched under $0.1 \mathrm{MPa}$ for $10 \mathrm{~min}$, and the stress was released instantaneously. Creep recovery process lasted for 10 min and strain as a function of time was recorded; stress relaxations of PUVs were measured using dynamic mechanical analyzer (DMA Q800, USA) at $130{ }^{\circ} \mathrm{C}, 140{ }^{\circ} \mathrm{C}$ and $150{ }^{\circ} \mathrm{C}$. The specimens were fixed at $1 \%$ strain so that stress changed to zero with time; stress as a function of time was recorded.

Qualitative elasticity shape memory test. The qualitative elasticity shape memory behavior of PUV-3 was evaluated by dynamic mechanical analyzer (DMA Q800, USA) in a strain mode of stretch. The three cycle tests of shape memory were carried out as follows: the sample was first heated to 80 ${ }^{\circ} \mathrm{C}$ with $30{ }^{\circ} \mathrm{C} \mathrm{min}^{-1}$. Then the sample was stretched under a load of $0.1 \mathrm{MPa}$ for $3 \mathrm{~min}$ and afterward cooled at $6^{\circ} \mathrm{C} \mathrm{min}^{-1}$ to $0{ }^{\circ} \mathrm{C}$ under the load. After subsequent unloading followed by a isothermal process for $3 \mathrm{~min}$, the recovery process was triggered by heating the sample back to $80{ }^{\circ} \mathrm{C}$ with a heating rate of $30{ }^{\circ} \mathrm{C} \mathrm{min}^{-1}$. The shape fixity ratio $\left(R_{\mathrm{f}}\right)$ and shape recovery ratio $\left(R_{\mathrm{r}}\right)$ were calculated using eqn (1) and (2):

$$
\begin{gathered}
R_{\mathrm{f}}=\frac{\varepsilon_{\text {unload }}}{\varepsilon_{\text {load }}} \times 100 \% \\
R_{\mathrm{r}}=\frac{\varepsilon_{\text {unload }}-\varepsilon_{\text {rec }}}{\varepsilon_{\text {unload }}} \times 100 \%
\end{gathered}
$$
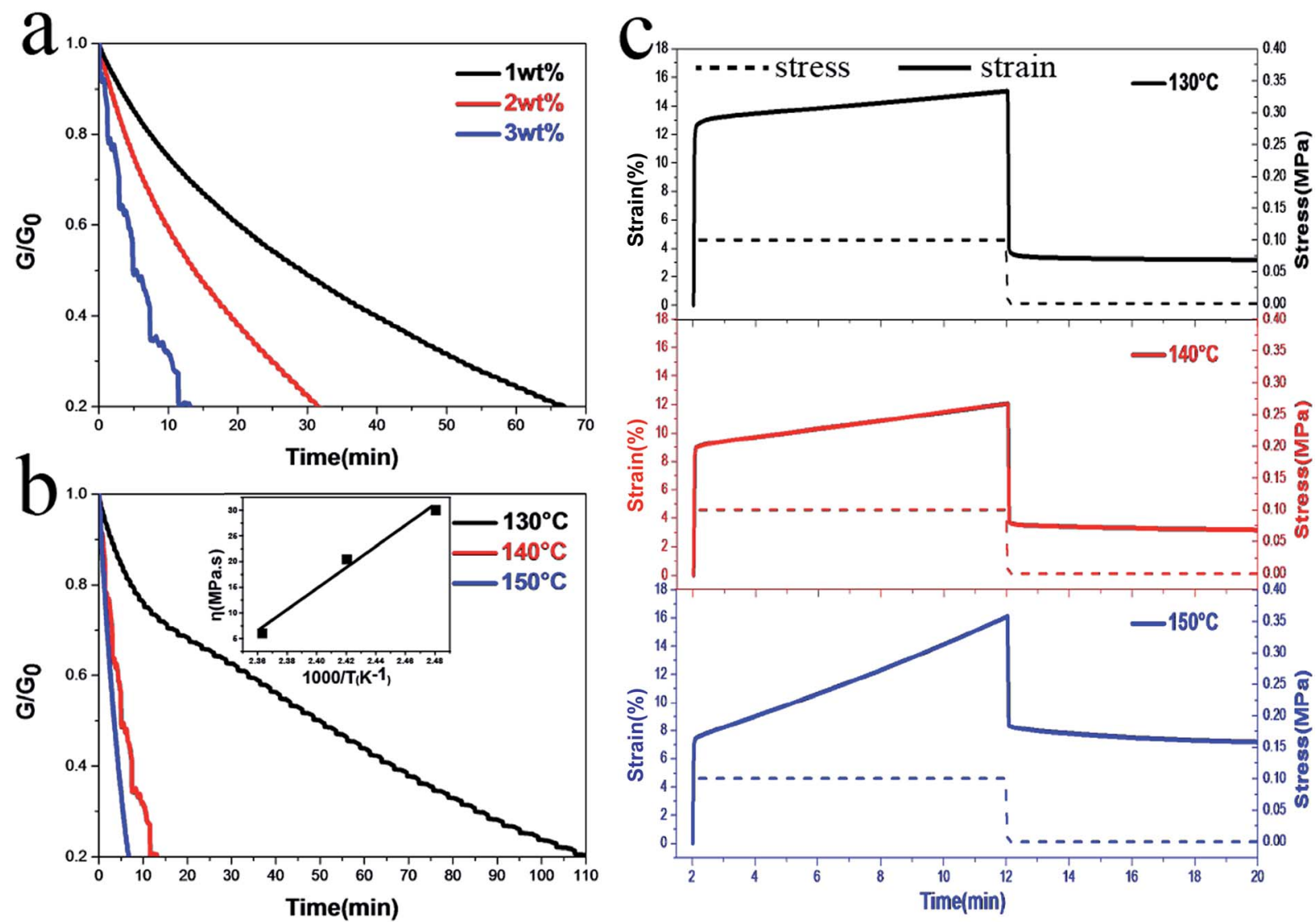

Fig. 3 (a) Stress relaxation behavior for various catalyst concentrations at $140{ }^{\circ} \mathrm{C}$. (b) Stress relaxation of the PUV-3 at various temperatures. (c) Creep and recovery curves of the PUV-3 at different temperatures. 
where $\varepsilon_{\text {unload }}, \varepsilon_{\text {load }}$ and $\varepsilon_{\text {rec }}$ are the fixed strain after the stress is completely relaxed, maximum strain under load and the strain after shape recover, respectively.

The thermally-induced dual-SME characterization. The thermally-induced dual-SME characterization of PUV-3 was examined using dynamic mechanical analyzer (DMA Q800, USA) under strain rate mode. The specimen was allowed to form a plasticity-based shape memory at a temperature ranging from $140{ }^{\circ} \mathrm{C}$ to $0{ }^{\circ} \mathrm{C}$, and an elasticity-based shape memory at temperature ranging from $80^{\circ} \mathrm{C}$ to $0{ }^{\circ} \mathrm{C}$. For 3 cycles in the same process, stress, strain and temperature as a function of time were recorded.

The morphology characterization of PUVs can be seen in ESI.†

\section{Results and discussion}

\section{Synthesis and characterization of PUVs}

PUVs were synthetized by PEG $\left(M_{\mathrm{n}}=2000\right)$, HDI and CO, using DBTDL as the catalyst. The chemical structures of all raw materials are shown in Fig. 1a. The FTIR spectroscopy results of CO, PEG, and pristine PUVs are shown in Fig. $4 \mathrm{~b}(1)-(5)$. It was observed that $\mathrm{C}-\mathrm{O}-\mathrm{C}$ symmetrical stretching vibration occurred at $1104 \mathrm{~cm}^{-1}$ and $\mathrm{C}-\mathrm{H}$ stretching/bending vibration appeared at $2885 \mathrm{~cm}^{-1}, 1469 \mathrm{~cm}^{-1}, 1344 \mathrm{~cm}^{-1}, 960 \mathrm{~cm}^{-1}$ and $840 \mathrm{~cm}^{-1}$ in the spectrum of pristine PUVs, which also appeared in the FTIR spectra of PEG. However, O-H stretching vibration peaks at $3430 \mathrm{~cm}^{-1}$ and the characteristic peak at $2265 \mathrm{~cm}^{-1}$, corresponding to $-\mathrm{N}=\mathrm{C}=\mathrm{O}$ of $\mathrm{HDI},{ }^{32}$ disappeared completely. The peak around $3426 \mathrm{~cm}^{-1}$ attributed to the $\mathrm{O}-\mathrm{H}$ stretching vibration of $\mathrm{CO}$ and the peak around $3433 \mathrm{~cm}^{-1}$ resulting from PEG also disappear completely. Furthermore, the spectra of PUVs result in new peak around at $1530 \mathrm{~cm}^{-1}$ belonging to the amide vibration of -NHCOO- groups. These results reveal that PUVs were successfully synthesized through chemical reactions of PEG, HDI and CO.

DSC and DMA were conducted for PUV-1, PUV-2 and PUV-3. The results are exhibited in Fig. 2. It shows that the networks have a melting transition at about $40{ }^{\circ} \mathrm{C}$ for the phase change of PEG without other peaks in Fig. 2b. All samples exhibited similar sharp drops from high storage modulus $\left(E^{\prime}=130 \mathrm{MPa}\right)$ at crystalline state to low storage modulus $\left(E^{\prime}=2 \mathrm{MPa}\right)$ at rubbery state, which could be identified in the curve of DMA (Fig. 2a). Therefore, it illustrated the formation of polymer networks and indicated that the networks have a potential ability for shape memory. As shown in the TGA curve of PUVs (Fig. 2c), the temperature at which the decomposition of polymers starts was about $300{ }^{\circ} \mathrm{C}$, whereas the content of catalyst had no effect on the thermal stability. The fastest weight loss occurred at about $430{ }^{\circ} \mathrm{C}$ for all samples, thereby indicating that PUVs exhibit a good thermal stability.

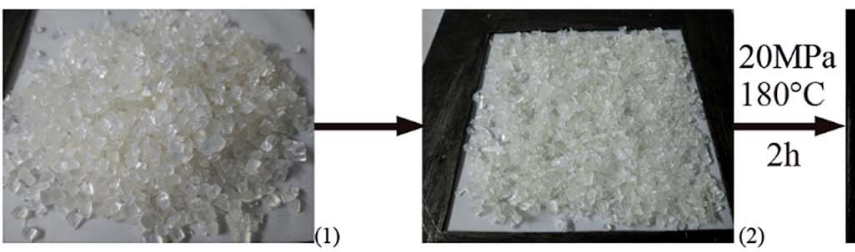

Broken into pieces
Placed into mold a

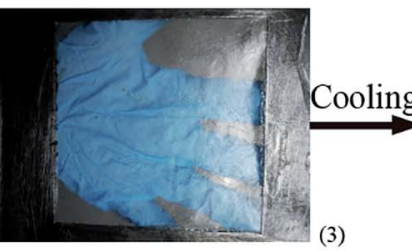

Mould pressing
(3)

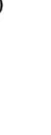
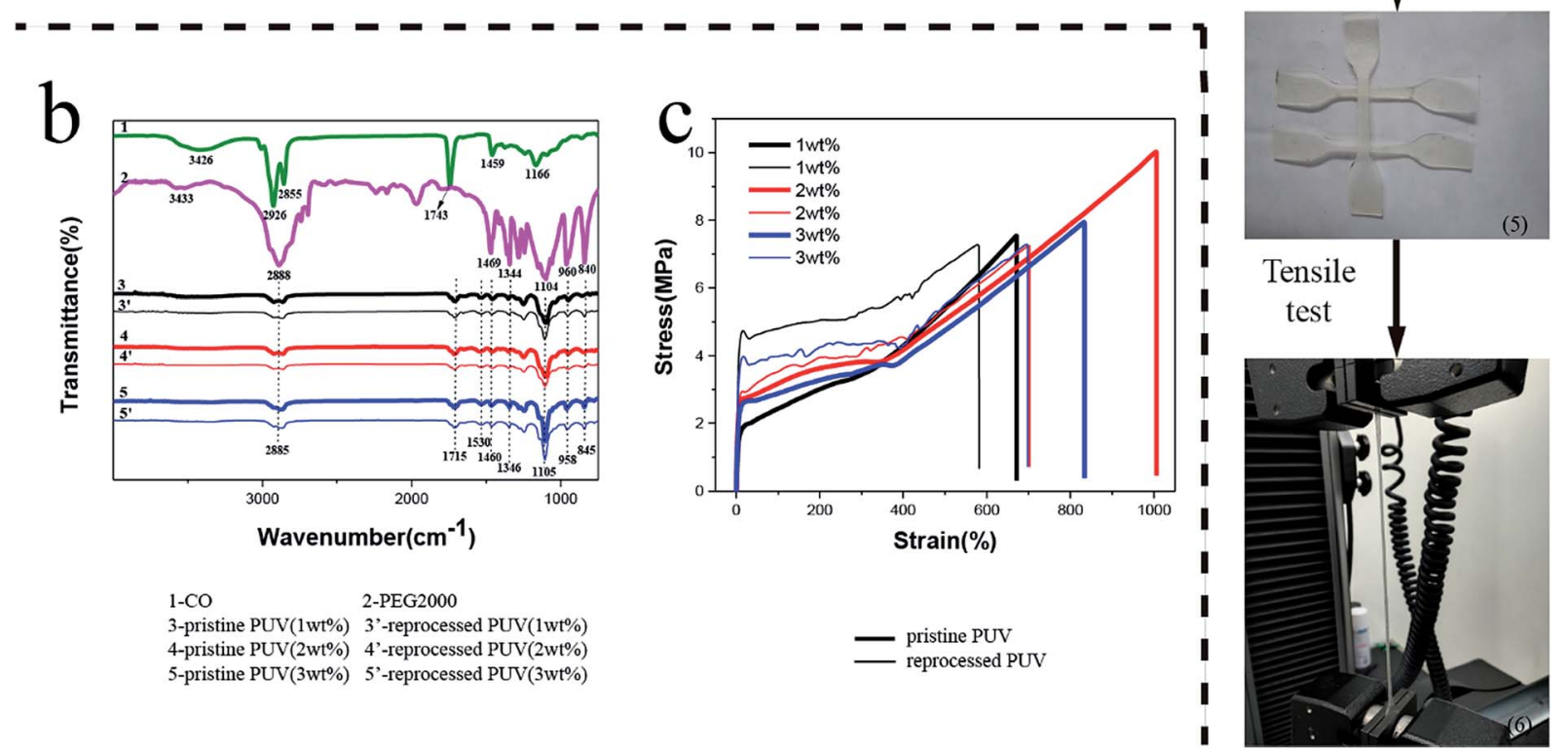

Fig. 4 (a) Diagram of reprocessing of the PUVs. (b) FTIR spectra of PEG, CO, pristine PUVs and reprocessed PUVs. (c) Tensile tests of the pristine PUVs and reprocessed PUVs. 

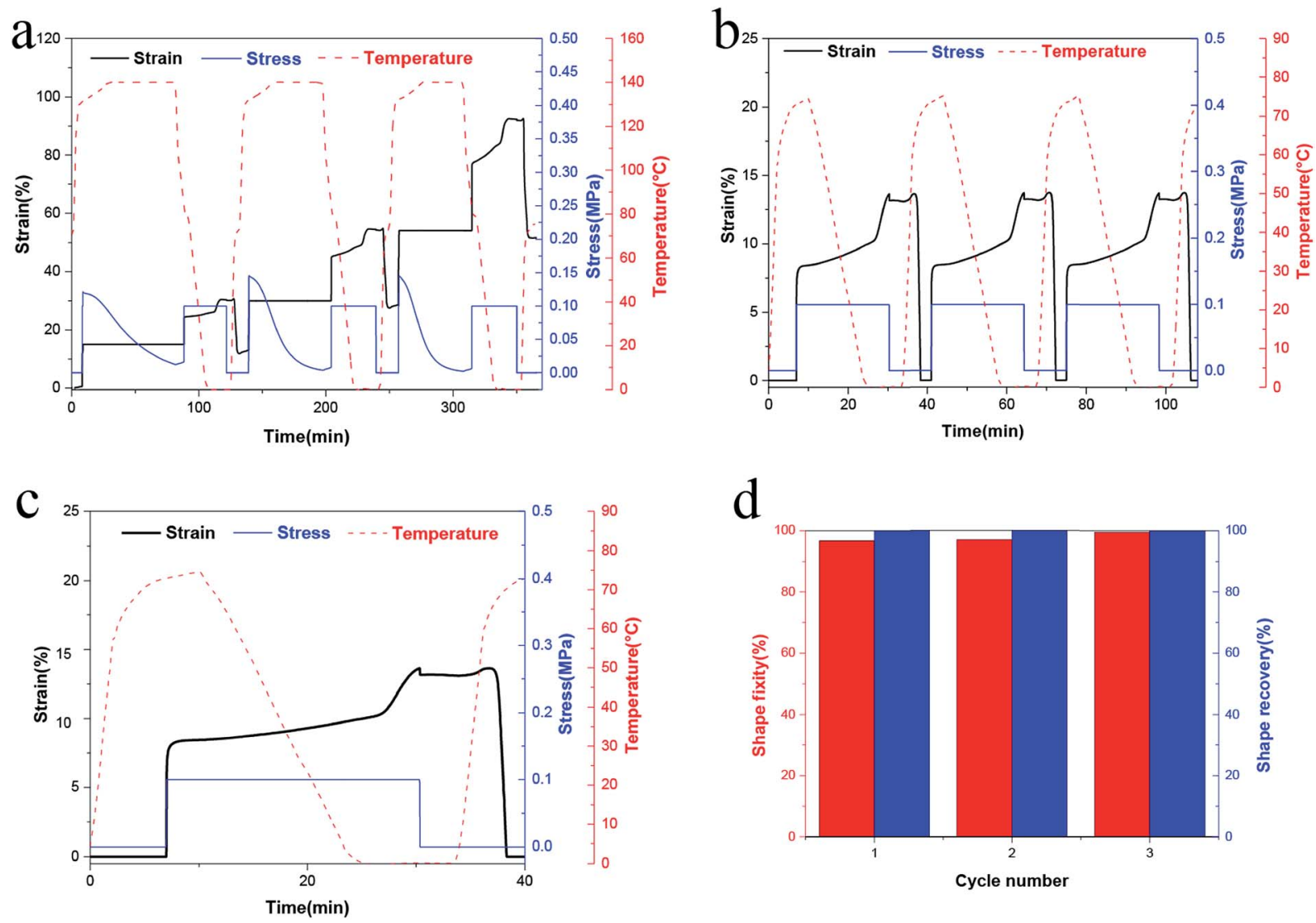

Fig. 5 (a) Consecutive elasticity/plasticity cycles. (b) Consecutive elasticity cycles. (c) A representative elasticity cycle. (d) Shape fixity $\left(R_{\mathrm{f}}\right)$ and shape recovery $\left(R_{\mathrm{r}}\right)$ ratio of the PUV-3 with the elasticity cycles.

The stress relaxation behavior of PUVs was observed to evaluate the rate of transcarbamoylation reaction. Fig. 3a shows that the samples with different contents of catalyst undergo stress relaxation at $140{ }^{\circ} \mathrm{C}$, suggesting that with higher catalyst content, PUV have much shorter relaxation times. In addition, it indicates that catalyst (DBTDL) was used for both polymerization and

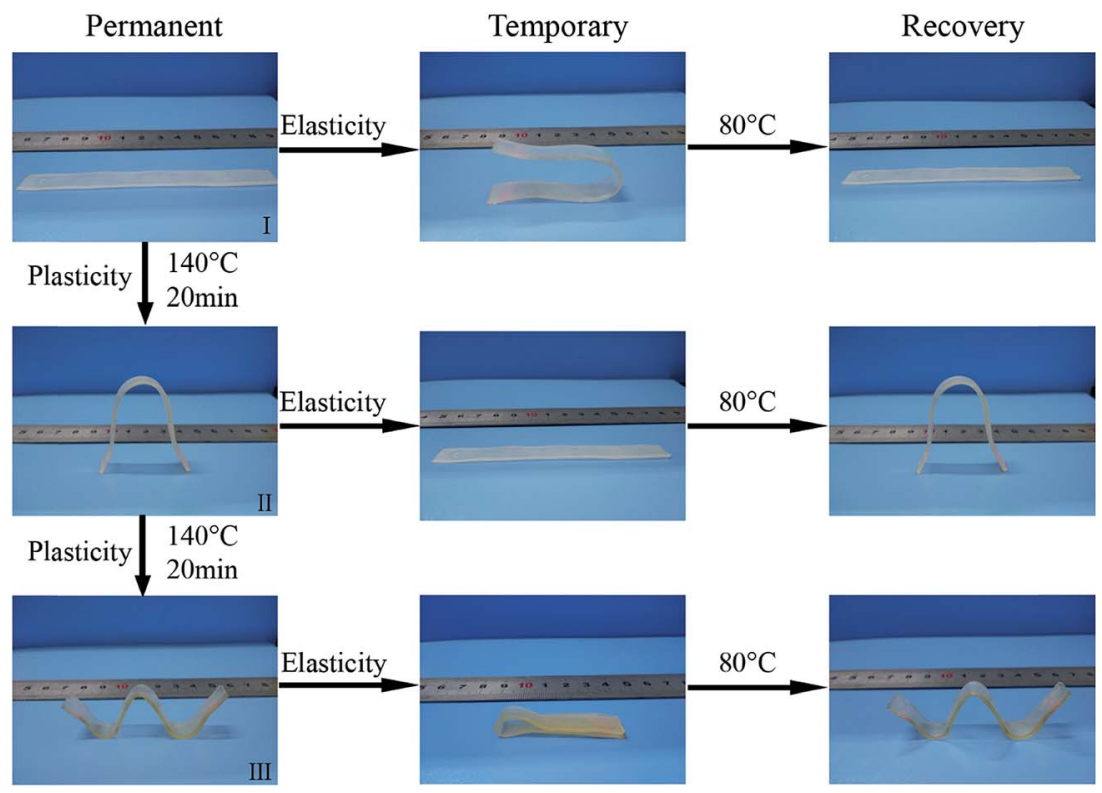

Fig. 6 Shape deformations via thermally distinct elasticity and plasticity. 
transcarbamoylation reaction and promoted the stress relaxation of PUVs. Fig. 3b shows that more time was required to undergo stress relaxation at a lower temperature under same relaxation degree and similar content of catalyst. This is because the temperature could promote stress relaxation of the networks or accelerate transcarbamoylation reaction of carbamate bonds. Therefore, above experiments further imply that thermallyactivated transcarbamoylation reactions of intrinsic carbamate bonds can change the topology of the networks. This can also be used for thermally-induced dual-SME and reprocessing of PUVs.

The temperature effect on the creep behavior of PUV-3 was studied, and the results are displayed in Fig. 3c, which shows that PUV-3 displays a preferable creep resistance at $130{ }^{\circ} \mathrm{C}$. Moreover, creep and recovery curve show that the strain of PUV-3 cannot be recovered completely after instantaneous stress release since transcarbamoylation reactions of carbamate bonds tend to rearrange the topology. In addition, we found that the strain recovery rate of the sample was the highest at $130{ }^{\circ} \mathrm{C}$ and lowest at $150{ }^{\circ} \mathrm{C}$, which was in accordance with the stress relaxation experiment results. Then, we choose $140{ }^{\circ} \mathrm{C}$ as the plasticity-based shape memory temperature. These combined observations indicate that PUVs have potential to reshape, reprocess and deform under relatively high temperature.

\section{Reprocessing of the crosslinked PUVs networks}

To demonstrate that thermoset polyurethanes have an ability of reprocessing, sample particles were molded into a film under $10 \mathrm{MPa}$ pressure for $2 \mathrm{~h}$ at $180^{\circ} \mathrm{C}$. As shown in Fig. $4 \mathrm{a}(3)$ and (4), the reprocessed polymers have a smooth and complete surface and display good mechanical property due to complete transcarbamoylation reaction. The tensile strength of pristine PUVs and reprocessed PUVs was evaluated, and the results are displayed in Fig. 4c. The yield strength, breaking strength and elongation at break of pristine PUV-3 were 2.7 MPa, 7.9 MPa and
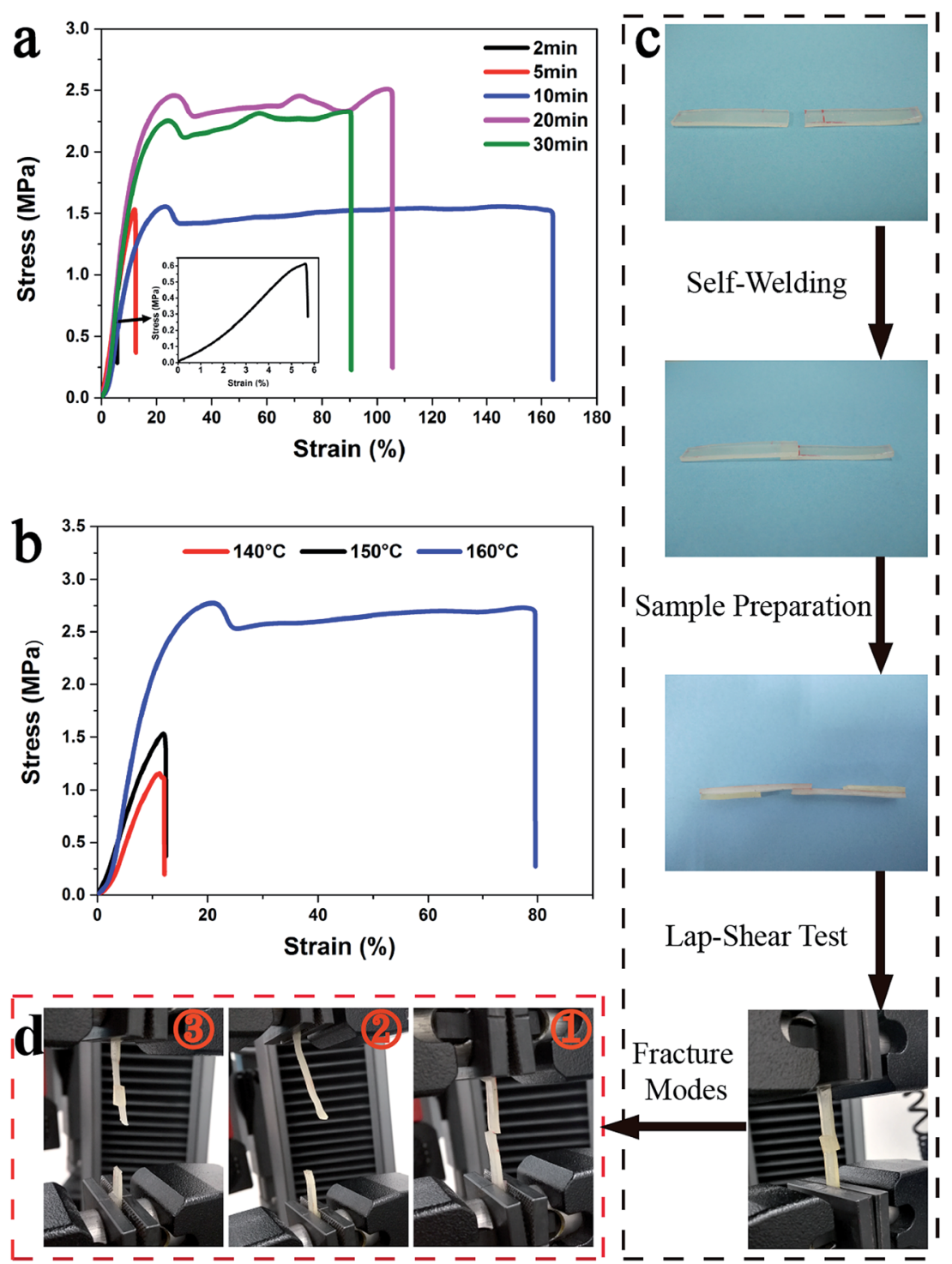

Fig. 7 The mechanical properties of the self-welded PUV-3 for (a) different time at $150{ }^{\circ} \mathrm{C}$ and (b) 5 min at different temperature. (c) Sample of the lap-shear test. (d) Fracture modes of the self-welded samples. 
$833.4 \%$, respectively. In comparison to control samples, breaking strength and elongation at break of the reprocessed PUV-3 were $7.3 \mathrm{MPa}$ (90\% recovery) and 698\% (85\% recovery), respectively. The incomplete recovery of tensile properties was caused by minor decomposition and some invisible defects in the networks, along with no vacuum in the reprocessing process. However, the yield strength of pristine PUV-3 was 3.9 MPa higher than that of the control sample, which may be due to an increase in crystallinity under high pressure in the course of processing. Recovery situation of other catalyst contents of reprocessed samples was similar to PUV-3. Furthermore, it can be observed that chemical structures of the reprocessed PUVs exhibit no change compared with pristine PUVs in the FTIR spectra Fig. $4 \mathrm{~b}(3)$ with $\left(3^{\prime}\right),(4)$ with $\left(4^{\prime}\right)$ and (5) with $\left(5^{\prime}\right)$.

\section{Property of thermally-induced dual-SME}

To investigate the property of distinct elasticity and plasticity shape memory, PUV-3 was subjected to consecutive shape memory cycles by DMA. As shown in Fig. 5a, three consecutive plasticity/elasticity cycles were evaluated through DMA under a strain mode. Within each cycle, a plasticity-based shape memory cycle was achieved with a high shape retention ratio of about $100 \%$, followed by an elasticity-based shape memory cycle. Consecutive elasticity-based shape memory cycles are shown in Fig. 5a and b representative elasticity-based shape memory cycle is shown in Fig. 5c. Importantly, the shape fixity ratio $R_{\mathrm{f}}$ is above $96 \%$ and shape recovery ratio $R_{\mathrm{r}}$ also reaches $100 \%$ within each cycle (Fig. $5 \mathrm{~d}$ ). All those cycle-to-cycle curves show a very little disparity of shape memory. Based on the obtained results, deformation of elasticity shape memory almost completely recovers and plasticity shape memory gains a good cumulation. These results suggest that the elasticity and plasticity of PUVs can be realized without any overlap.

As shown in Fig. 6, the original shape is a rectangle film. The sample can be plastically deformed into a permanent shape " $\mathrm{V}$ " by simply applying a fold force through a complete transcarbamoylation of carbamate bonds at $140{ }^{\circ} \mathrm{C}$ for $20 \mathrm{~min}$ (Fig. 6(II)). This permanent shape can further display an elasticitybased temporary shape memory. Importantly, this permanent shape "V" can be further deformed plastically into the "W" shape (Fig. 6(III)) or another shape under the same condition, which also can be fixed into some recoverable temporary shapes. Furthermore, Fig. $2 d$ shows that the cylinder can still keep the shape unchanged even on heating at $150{ }^{\circ} \mathrm{C}$ for $30 \mathrm{~min}$, confirming that the plastic permanent deformation does not require material flow. The topological changes of the networks and molecular chain motion can be seen in Fig. 1b. It can be considered that PEG chain segments through phase transformation above $T_{\text {trans }}$ and carbamate bonds via transcarbamoylation reactions at a corresponding $T_{\mathrm{p}}$ (ref. 24) can endow the shape memory with thermally distinct elasticity and plasticity to PUVs.

\section{Ability of self-welding}

The self-welding experiment of fracture surface of PUV-3 indicates that PUVs have the ability of self-welding (Fig. S3†). To further investigate the self-welding efficiency, lap-shear tests of welded samples were carried out (the detailed procedure is described in the ESI $\dagger$ ). As shown in Fig. 7a, the stress of welded samples tended to increase with welding time at a fixed temperature. It is worth noting that the welded samples with welding time of $2 \mathrm{~min}, 5 \mathrm{~min}$ (Fig. 7d(1)) and $10 \mathrm{~min}$ (Fig. 7d(2) all broke at the overlapped part and had relatively lower stress at break. However, the welded samples under same temperature but with a longer heating time (20 $\mathrm{min}$ and $30 \mathrm{~min}$ ) had stress at break higher than $2 \mathrm{MPa}$. The welded samples broke at bulk material instead of the overlapped part (Fig. 7d(3) because of nearly complete transcarbamoylation reaction at the overlapped part. It can be seen in Fig. $7 \mathrm{~b}$ that higher temperature promotes better welding ability with the same welding time. Importantly, welded samples (at $140{ }^{\circ} \mathrm{C}$ and $150{ }^{\circ} \mathrm{C}$ ) that broke at the overlapped part (Fig. 7d(1)) had a relatively lower stress at break, but the welded samples (at $160{ }^{\circ} \mathrm{C}$ ) that broke at bulk material part (Fig. 7d(3) had relatively higher stress at break. Thus, it has demonstrated that PUVs have good ability of self-welding.

\section{Conclusion}

In summary, PUVs based on transcarbamoylation of carbamates with the ability of reprocessing, thermally-induced dualSME and self-welding have been prepared by conditional polyaddition method based on renewable and biodegradable castor oil. The reprocessed crosslinked PUVs have nearly same tensile properties compared with pristine PUVs. In addition, we systematically studied their property of distinctly thermal plasticity and thermal elasticity shape memory and a series of complex deformations. Moreover, the self-welding property of PUVs was realized. Importantly, by combining the properties of traditional thermosets and thermoplastic, supported by dynamic covalent bonds, PUVs could have a wide variety of future engineering applications and even provide an effective way to solve the problems arising due to waste generation and accumulation of the abandoned crosslinked polyurethane polymers.

\section{References}

1 W. Denissen, G. Rivero, R. Nicolaÿ, L. Leibler, J. M. Winne and F. E. Du Prez, Adv. Funct. Mater., 2015, 25, 2451.

2 G. Müller and B. Rieger, Prog. Polym. Sci., 2002, 27, 815.

3 M. Dasdemir, B. Maze, N. Anantharamaiah and B. Pourdeyhimi, J. Mater. Sci., 2011, 46, 3269.

4 T. Vidil, F. Tournilhac, S. Musso, A. Robisson and L. Leibler, Prog. Polym. Sci., 2016, 62, 126.

5 D. Crespy, M. Bozonnet and M. Meier, Angew. Chem., Int. Ed., 2008, 47, 3322.

6 D. Montarnal, M. Capelot, F. Tournilhac and L. Leibler, Science, 2011, 334, 965.

7 M. Capelot, D. Montarnal, F. Tournilhac and L. Leibler, J. Am. Chem. Soc., 2012, 134, 7664.

8 M. Capelot, M. M. Unterlass, F. Tournilhac and L. Leibler, ACS Macro Lett., 2012, 1, 789. 
9 F. Snijkers, R. Pasquino and A. Maffezzoli, Soft Matter, 2017, 13(1), 258-268.

10 W. Denissen, J. M. Winne and F. E. Du Prez, Chem. Sci., 2015, 7, 3 .

11 K. Yu, P. Taynton, W. Zhang, M. L. Dunnd and H. J. Qi, RSC Adv., 2014, 4, 10108.

12 A. Ruiz De Luzuriaga, J. M. Matxain, F. Ruipérez, R. Martin, J. M. Asua, G. Cabañero and I. Odriozola, J. Mater. Chem. C, 2016, 4, 6220.

13 R. Martin, A. Rekondo, A. R. De Luzuriaga, G. C. N. Odriozola, H. J. Grande and I. Odriozola, J. Mater. Chem. A, 2014, 2, 5710.

14 Y. Yang, Z. Pei, Z. Li, Y. Wei and Y. Ji, J. Am. Chem. Soc., 2016, 138, 2118.

15 M. M. Obadia, B. P. Mudraboyina, A. Serghei, D. Montarnal and E. Drockenmuller, J. Am. Chem. Soc., 2015, 137, 6078.

16 Q. Chen, X. Yu, Z. Pei, Y. Yang, Y. Wei and Y. Ji, Chem. Sci., 2017, 8(1), 724-733.

17 Z. Pei, Y. Yang, Q. Chen, Y. Wei and Y. Ji, Adv. Mater., 2016, 28, 156.

18 M. Pepels, I. Filot, B. Klumperman and H. Goossens, Polym. Chem., 2013, 4, 4955.

19 E. Chabert, J. Vial, J. Cauchois, M. Mihaluta and F. Tournilhac, Soft Matter, 2016, 12, 4838.
20 A. Rekondo, R. Martin, A. Ruiz De Luzuriaga, G. Cabañero, H. J. Grande and I. Odriozola, Mater. Horiz., 2014, 1, 237.

21 O. R. Cromwell, J. Chung and Z. Guan, J. Am. Chem. Soc., 2015, 137, 6492.

22 Q. Zhao, W. Zou, Y. Luo and T. Xie, Sci. Adv., 2016, 2, e1501297.

23 N. Zheng, Z. Fang, W. Zou, Q. Zhao and T. Xie, Angew. Chem., 2016, 128, 11593.

24 Q. Zhao, H. J. Qi and T. Xie, Prog. Polym. Sci., 2015, 49-50, 79.

25 Z. Yang, Q. Wang and T. Wang, ACS Appl. Mater. Interfaces, 2016, 8, 21691.

26 F. I. Altuna, C. E. Hoppe and R. J. J. Williams, RSC Adv., 2016, 6, 88647 .

27 D. J. Fortman, J. P. Brutman, C. J. Cramer, M. A. Hillmyer and W. R. Dichtel, J. Am. Chem. Soc., 2015, 137, 14019.

28 Z. M. Liu, X. W. Fu, L. Jiang, B. Wu, J. L. Wang and J. X. Lei, Sol. Energy Mater. Sol. Cells, 2016, 147, 177.

29 H. Mutlu and M. A. R. Meier, Eur. J. Lipid Sci. Technol., 2010, 112, 10.

30 S. R. Crowell, J. N. Smith, J. A. Creim, W. Faber and J. G. Teeguarden, Regul. Toxicol. Pharmacol., 2015, 73, 452.

31 W. Liu, X. Zhang, L. Dai and S. You, Angew. Chem., Int. Ed., 2012, 51, 5183.

32 X. Zhou, J. Appl. Polym. Sci., 2009, 113, 2041. 